\title{
Physical Properties of Biomass Fuel Briquette from Oil Palm Residues
}

\author{
${ }^{1}$ MURAINA, HO; ${ }^{* 2}$ ODUSOTE, JK; ${ }^{3}$ ADELEKE, AA \\ ${ }^{1,3}$ Department of Mechanical Engineering, University of Ilorin, Nigeria \\ ${ }^{*}$ Department of Materials and Metallurgical Engineering, University of Ilorin, Nigeria \\ *Corresponding author e-mail: jamiukolawole@gmail.com
}

\begin{abstract}
Palm Kernel Shell (PKS) and Mesocarp Fibre (MF) were used for the production of fuel briquettes in this study in order to supplement the energy mix of the nation. PKS was pulverized and then sieved into different grain particles of $350 \mu \mathrm{m}, 250 \mu \mathrm{m}$ and $150 \mu \mathrm{m}$, before mixing with MF in the ratios: 90:10, 80:20 and 70:30 (PKS: MF respectively). Cassava Peel (CP) was used as binder for the briquettes. A $200 \mathrm{kN}$ force was exerted during densification while the waiting time for the briquettes to properly form was 120 seconds. Proximate/physical analysis was carried out and the results showed that briquette series of $150 \mu \mathrm{m}$ (80:20) has the minimum moisture content of $6.00 \%$ while series $350 \mu \mathrm{m}(90: 10)$ recorded the lowest ash content of $1.50 \%$. Volatile matter of $72.80 \%$ was recorded from series $150 \mu \mathrm{m}$ (70:30) as the highest of all the series produced. Briquette series of $350 \mu \mathrm{m}(70: 30)$ have the highest fixed carbon and calorific value of $19.90 \%$ and $18.1063 \mathrm{~kJ} / \mathrm{g}$, respectively. The results showed that the fuel briquettes from PKS and MF (especially $350 \mu \mathrm{m}$ series) could serve as alternative source of energy for domestic and industrial applications. (C) JASEM
\end{abstract}

\section{https://dx.doi.org/10.4314/jasem.v21i4.19}

Keywords: Palm kernel shell; Mesocarp fibre; Briquette; Biomass solid fuel; proximate analysis.

The major source of energy in most developing countries of the world including Nigeria is the fossil fuel (Plumer, 2014). Apart from instability in the price of fossil fuel in the world market, scarcity and non-renewability are some of the challenges being faced by the countries relying on this fuel for energy production. Continuous fluctuation in the price of fossil fuel in the world market is impacting negatively on the economy of most oil producing developing countries, such as Nigeria. Other drawback to the use of fossil fuel as only source of energy is the negative impact of its effluents on the environment resulting in global warming.

Global warming is a phenomenon that has negative impact on the environment and its effects can be eliminated through the introduction of green technology. Green technology comprises of proper utilization of plants or agriculture remnants which are considered wastes and converting them to more useful products that can be applied in many sectors including power and energy (Chan-Mo, 2010; Fujii and Yamaji, 1998).

Recycling of abundant agricultural wastes in Africa into solid fuel will not only salvage the environment from various health challenges but will also improve the energy mix of these countries. Most Nigerians especially those in the rural communities depend on fuel wood as the major source of energy, which aggravates deforestation. However, this can greatly be reduced if available agricultural wastes can be converted into energy source. Forests keeping enhance ventilation, beautify surroundings, serve as strong wind breaker and more importantly reduce the effect of greenhouse gases.

Nigeria is one of the major producers of palm oil in the world after Malaysia and Indonesia (Akinbami, 2001; IETC, 2009; Ugwu and Agbo, 2011). However, Palm Kernel Shell (PKS) and Mesocarp Fibre (MF) from the production process of palm oil have been treated as waste and discarded indiscriminately. These wastes have mostly been burnt, throw in the river and sometimes used locally by the rural dwellers for cooking but continue to be a source of pollution as the GHG emission remain high. Therefore, the physical properties of fuel briquettes produced from oil palm residues (PKS and MF) are investigated in this study in order to determine their suitability as energy source for domestic and industrial purposes.

\section{MATERIALS AND METHOD}

Sample Collection and Preparation: Palm kernel shell and mesocarp fibre used in this study were sourced from Araromi Otunla; a hamlet village in Ilesa, Osun state. Dirt and foreign materials such as sand, stone, ashes and plant residues were removed from the as-received palm kernel shells (PKS) by sieving. It was then washed thrice with water and sun dried for 4 days at an average of $4 \mathrm{hrs} /$ day. In addition, fibrous mesocarp was carefully washed and sun dried for 4 days at an average of $4 \mathrm{hrs} /$ day with the washing period extended to four times inherently due to large presence of palm oil.

Sample Analysis: Palm kernel shell (PKS) was pulverized and then sieved to British Standard (BSS) at $350 \mu \mathrm{m}, 250 \mu \mathrm{m}$ and $150 \mu \mathrm{m}$ with Octagon digital sieving machine. This was followed by mixing the 
sieved PKS and MF in different proportions with cassava peel $(\mathrm{CP})$ as binder, in order to enhance the homogeneity of the aggregates. Mixing ratios of Palm Kernel Shell (PKS) to Mesocarp Fibre (MF) adopted are 90 to 10,80 to 20 and 70 to 30 , respectively. Binder used was $30 \%$ of the entire mass of the aggregates while $500 \mathrm{ml}$ of water was used. Mixing of the PKS, MF and CP was done using a manual stirrer. The mixture (feedstock) was then poured into a prepared mould. Compaction was done using EL31 $0721560 \mathrm{kN}$ manual hydraulic jack machine. The mould was placed in between the compressive plates of the machine and piston was manually released from above and allowed to exert force of $200 \mathrm{kN}$ on the aggregates. The dwelling time was 120 seconds for every briquette produced. Each proportion of the aggregates was repeated four times. The briquette was carefully ejected from the mould having adjusted the piston for its removal. The briquette samples were later sun dried for one week in order to allow the residual moisture and palm oil to dry.

Physical Analysis of the Fuel Briquette Sample: The proximate analysis indicates the percentage by weight of fixed carbon, volatiles, ashes and moisture contents in the biomass.

Moisture Content Determination (MC): A $2 \mathrm{~g}$ from each of the samples, $W_{o}$, was placed in an uncovered crucible which was then placed in the oven kept at $108 \pm 2{ }^{\circ} \mathrm{C}$. The sample was then allowed to cool to room temperature until a constant weight, $\mathrm{W}_{\mathrm{f}}$, was reached and re-weighed. The loss in the weight of each sample expressed as a percentage of $W_{f}$ represents the moisture content (MC) on dry basis as given in Equation 1 (UNEP, 2006).

$$
M C=\frac{W_{o}-W_{f}}{W_{f}} \times 100 \%
$$

Ash Content Determination (AC): Approximately $2 \mathrm{~g}$ of finely grounded, oven dried sample was placed in a porcelain crucible and weighed, $\mathrm{W}_{1}$, before it was transferred into a preheated muffle furnace at $900{ }^{\circ} \mathrm{C}$. The sample was left inside the furnace for an hour after which the crucible with the content was transferred to a desiccator and allowed to cool. The crucible with its content was re-weighed, $W_{f}$, and the weight of the empty crucible, $W_{C}$, was also taken. The percentage ash content (dry basis) is calculated using Equation 2 (UNEP, 2006).
$\%$ Ash content $=\frac{w_{f}-w_{C}}{w_{1}-w_{C}} \times 100 \%$

Volatile Content Determination (VC): Approximately $2 \mathrm{~g}$ of the air-dried samples of the biomass feedstock, $W_{1}$, was heated at about $900^{\circ} \mathrm{C}$ for 7 minutes in a partially enclosed porcelain crucible, placed in a furnace. The crucible was retrieved and left to cool in a desiccator. The weight of the residue (VC) was determined from Equation 3 (UNEP, 2006).

$V C=\frac{W_{1}-W_{f}}{W_{f}} \times 100 \%$

where $W_{f}$ is the weight of samples after oven drying.

Fixed Carbon Determination $(F C)$ : The fixed carbon content was determined by removing the sum of the moisture (MC), volatile matter (VC) and Ash contents (AC) from $100 \%$ as shown in Equation 4 (UNEP, 2006).

$F C=100-(M C+V C+A C)$

Higher Heating Value Determination (HHV): The higher heating value which is otherwise known as calorific value was determined to evaluate the percentage heat dispensed by the solid fuel. Parikh formula is one of the models developed to accurately investigate the HHV of biomass (Parikh et al., 2005). Parikh formula has an absolute error of $3.74 \%$ and bias error of $0.12 \%$ as compared to Demibras, Jimenez, Cordero and Kucukkayrak models (Parikh et al., 2005). Equation 5 is the Parikh formula that was used in this study to obtain HHV of the briquettes from the proximate analysis.

$$
\begin{aligned}
& H H V=0.3536 F C+0.1559 V M-0.0078 A S H(k J / \\
& g)
\end{aligned}
$$

where $\mathrm{FC}=\%$ Fixed Carbon, $\mathrm{VM}=\%$ Volatile Matter, $\mathrm{ASH}=\%$ Ash content.

\section{RESULTS AND DISCUSSIONS}

Physical Properties of the Fuel Samples: Table 1 shows the proximate analysis and higher heating value of the biomass briquettes in their respective ratios and particle sizes compared with other biomass solid fuels. The results of the moisture, ash, volatile matter and percentage fixed carbon of the biomass briquettes revealed that they can be suitable for use as fuels in domestic and industrial applications. These results were compared with the findings of other authors (Ilochi, 2010; Onuegbu et al., 2010; Akowuah et al., 2012; Chin Yee and Shiraz, 2013) as shown in Table 1. 
Table 1 Proximate Analysis and Higher Heating Value of Briquette Samples of different Grain Sizes and Composition

\begin{tabular}{|c|c|c|c|c|c|c|c|}
\hline $\begin{array}{l}\text { Biomass Solid } \\
\text { Fuels }\end{array}$ & $\begin{array}{l}\text { Grain Sizes } \\
(\mu \mathrm{m})\end{array}$ & $\begin{array}{l}\text { Moisture } \\
(\%)\end{array}$ & $\begin{array}{l}\text { Ash } \\
(\%)\end{array}$ & $\begin{array}{l}\text { Volatile Matter } \\
(\%)\end{array}$ & $\begin{array}{l}\text { Fixed Carbon } \\
(\%)\end{array}$ & $\begin{array}{l}\mathrm{HHV} \\
(\mathrm{kJ} / \mathrm{g})\end{array}$ & References \\
\hline 90PKS:10MF. & 350 & 9.90 & 1.50 & 69.80 & 19.50 & 17.7653 & Present study \\
\hline 80PKS:20MF & 350 & 9.00 & 1.70 & 70.00 & 19.30 & 17.5822 & Present study \\
\hline 70PKS:30MF & 350 & 7.10 & 1.90 & 71.10 & 19.90 & 18.1063 & Present study \\
\hline 90PKS:10MF & 250 & 8.50 & 3.00 & 71.00 & 17.51 & 17.2370 & Present study \\
\hline 80PKS:20MF & 250 & 7.00 & 3.19 & 71.20 & 18.61 & 17.6557 & Present study \\
\hline 70PKS:30MF & 250 & 6.50 & 3.27 & 72.10 & 18.13 & 17.6257 & Present study \\
\hline 90PKS:10MF & 150 & 8.00 & 3.50 & 72.10 & 16.40 & 17.0121 & Present study \\
\hline 80PKS:20MF & 150 & 6.00 & 3.61 & 72.50 & 17.89 & 17.6005 & Present study \\
\hline 70PKS:30MF & 150 & 6.30 & 3.70 & 72.80 & 17.20 & 17.4026 & Present study \\
\hline Coal & -- & 6.10 & 14.00 & 23.00 & 56.90 & 21.2563 & (Ilochi, 2010) \\
\hline Groundnut shell & --- & 10.30 & 6.00 & 54.70 & 29.00 & 14.4037 & (Ilochi, 2010) \\
\hline Corn cob & --- & 12.20 & 3.30 & 54.60 & 29.90 & 16.4047 & (Ilochi, 2010) \\
\hline Spear Grass & --- & 9.26 & 6.18 & 69.10 & 15.46 & 14.6600 & $\begin{array}{l}\text { (Onuegbu, et al., } \\
2010)\end{array}$ \\
\hline Saw dust & -- & 5.70 & 2.6 & 71.00 & 20.70 & --- & $\begin{array}{l}\text { (Akowuah et al., } \\
\text { 2012) }\end{array}$ \\
\hline $60 \mathrm{PKS}: 40 \mathrm{PF}^{\circ}$ & $63-500$ & -- & 6.02 & 71.81 & 22.16 & 18.6300 & $\begin{array}{l}\text { (Chin Yee and Shiraz, } \\
\text { 2013) }\end{array}$ \\
\hline
\end{tabular}

- PKS:MF = Palm kernel shell: Mesocarp fibre $\quad{ }^{\circ} \mathrm{PKS}: \mathrm{PF}=$ Palm kernel shell:Palm fibre

Moisture Content Percentage: Moisture content percentage is an important parameter in briquette production. Figure 1 indicates the moisture content concentration of the briquettes with different grain particles and mixing ratios. Briquette $350 \mu \mathrm{m}$ (90:10) aggregate had the highest percentage moisture, followed by $350 \mu \mathrm{m}(80: 20)$ and $250 \mu \mathrm{m}$ (90:10). Since the briquettes was sun dried and in relation to the particle size of the PKS $(350 \mu \mathrm{m})$, briquettes with finer grain particles tend to dry faster while those with larger particle have more moisture percentage as it took more time for them to dry up. Aggregate 70:30 briquette series have least moisture as compared to others. In this regard, it can be inferred that particle size is one parameter that is very important when considering the dryness factor of any briquette. Besides, the dryness difference at $350 \mu \mathrm{m}, 250 \mu \mathrm{m}$ and $150 \mu \mathrm{m}$ (70:30) as compared to the other mixing ratios respectively could be due to change in climatic condition during sun drying. The percentage moisture contents however, are still within the expected percentage as explained by Shaha (1974); Kaliyan and Morey (2006). Table 1 shows that the moisture content results obtained for this work is good enough compared to those from coal, spear grass and saw dust briquettes (Ilochi, 2010, Onuegbu et al., 2010 and Akowuah et al., 2012). The little difference in the moisture content as shown in Table 1 could be as a result of the production process or the drying medium adopted in the previous work which could be of advantage over sun drying.

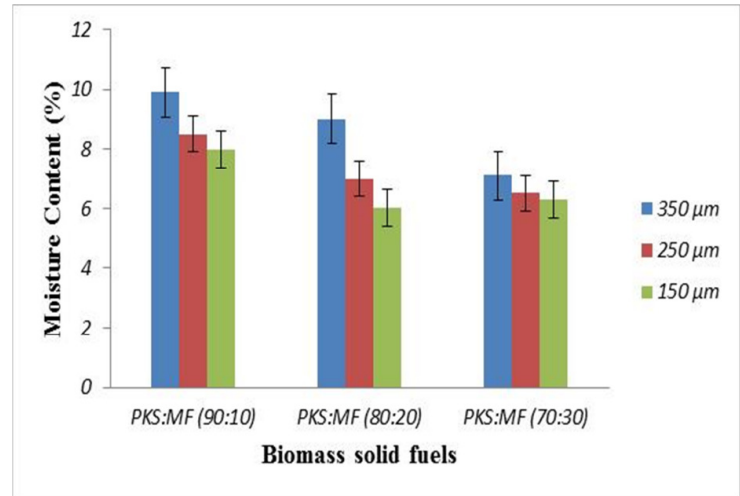

Fig. 1: Percentage Moisture Content of Briquette Samples in Different Mixing Ratios of Palm KernelShell (PKS) and Mesocarp Fibre (MF).

Ash Content Percentage: Figure 2 shows the ash content percentage of the briquettes. At series $350 \mu \mathrm{m}$ aggregates, there is a seldom increase of $0.2 \%$ in the percentage ash content. This however, is not the same for $250 \mu \mathrm{m}$ and $150 \mu \mathrm{m}$ aggregates as the ash content increase in a random manner. As shown in Figure 2, the percentage ash content increase with increase in the mesocarp fibre and directly proportional to the grain particles. Finer grain particles are expected to ignite fast and have a speedy combustion. The fast combustion rate will allow them burn to ash especially more than the bigger particle sizes which is agrees with the report of Chin Yee and Shiraz (2013). It was shown from their work that increases in the palm fibre (mesocarp fibre) lead to increase in the ash concentration. The reason for this may probably be due to the fact that mesocarp fibre displays good burning characteristics and mostly uniform combustion. They ignite easily compared to PKS and are expected to burn and turn to ash faster. The ash content percentages of the present briquettes compete 
favourably with previous briquettes produced from saw dust with $2.6 \%$ (Akowuah et al., 2012) and spear grass with $6.18 \%$ (Onuegbu et al., 2010) as shown in Table 1. Ash content percentage is expected to be between 5 and $40 \%$ as their excess is detrimental for proper combustion of solid fuels (UNEP, 2006; Shaha, 1974). The ash content percentages recorded for this work shows that they are even better than coal samples as reported by Ilochi (2010).

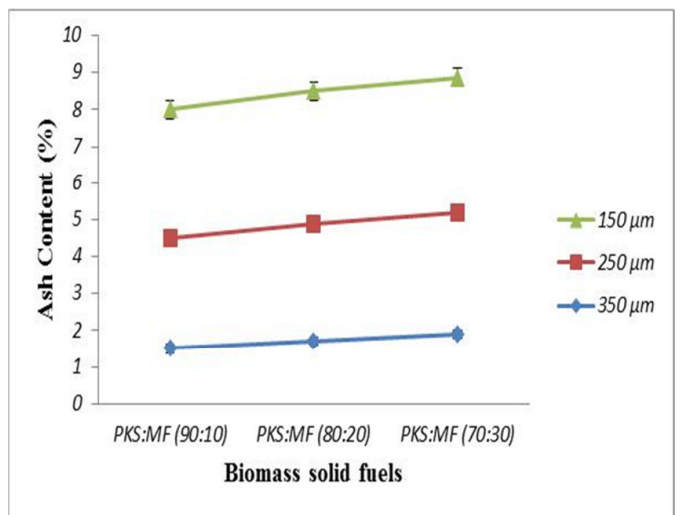

Fig. 2: Percentage Ash Content of Palm Kernel Shell (PKS) and Mesocarp Fibre (MF) at different particle size and mixing Ratios.

Volatile Matter Percentage: Figure 3 shows the percentage volatile matters of the solid fuels with varying grain particles and mixing ratios. Solid fuels in series $150 \mu \mathrm{m}$ have the highest percentage, followed by $250 \mu \mathrm{m}$ and $350 \mu \mathrm{m}$ series. The variance in the volatile matter content may be as a result of improper mixing of the aggregates during production which may result to trapping of incombustible gases like nitrogen and carbon dioxide. Figure 3 shows that the volatile matter increases as the mesocarp fibre increases and the bigger the grain particles, the smaller the volatile matter. Percentage volatile matter indicates the easiness of any fuel sample to ignite, thus the results of the present study shows that the briquettes can ignite easily with or without aids e.g. kerosene. The values obtained show that the volatile matter contents of the current solid fuels are more compared with the works of Chin Yee and Shiraz (2013) as well as those of coal, spear grass and saw dust (Ilochi, 2010; Onuegbu et al., 2010; Akowuah et al., 2012) as shown in Table 1. Aggregates of palm kernel shell and mesocarp fibre could have a high volatile matter especially when there is an appreciable percentage of mesocarp fibre and considerable high grain sizes of palm kernel shell. Therefore, high percentage in the volatile matter for the present work is justified. However, the value obtained for spear grass (Ilochi, 2010) could be due to the grain particle used in the mixing ratio.

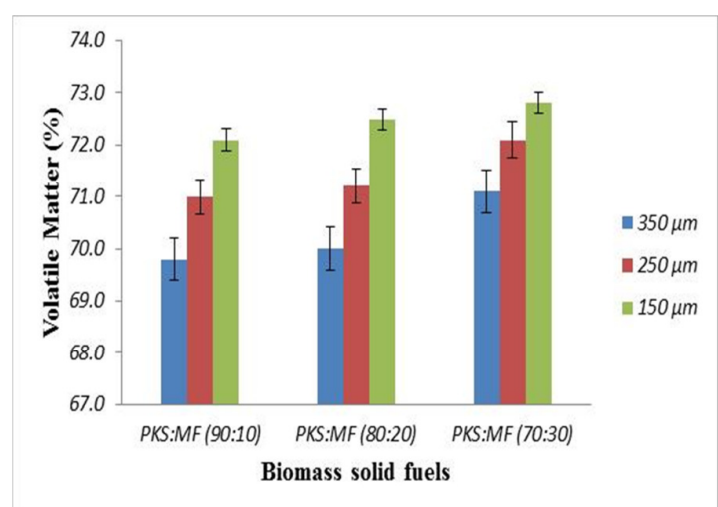

Fig. 3: The Percentage Volatile Matter of PKS: MF Ratios at different grain sizes and mixing ratios.

Fixed Carbon Percentage: The percentage fixed carbon of the fuel samples is presented in Figure 4. The figure shows that there is a seldom reduction in the fixed carbon percentage especially in series 350 $\mu \mathrm{m}$. Reverse is the case at the series $250 \mu \mathrm{m}$ and 150 $\mu \mathrm{m}$ as the percentage fixed carbon showed a bit of fluctuation in the values. Percentage fixed carbon value must be high in order to obtain a better calorific value for any solid fuels. It was initially stated that finer grains display a good ignition property, yet they may not necessarily have the best fixed carbon as displayed by series $350 \mu \mathrm{m}$ having better percentage fixed carbon which could be as a result of the bigger grain particles of the palm kernel shell in the aggregates. The fixed carbon contents of coal, groundnut shell, corn cob and saw dust (Ilochi, 2010; Onuegbu et al., 2010 and Akowuah et al., 2012) as shown in Table 1 are in close range to those obtained in this present study and thus suggest that they are good as solid fuels.

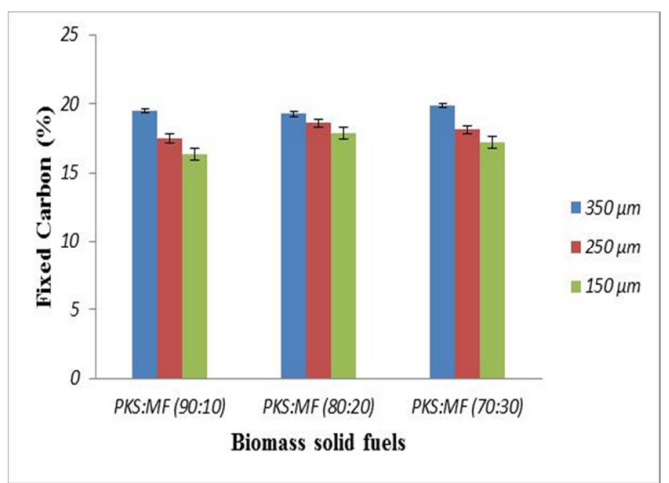

Fig. 4: The Fixed Carbon Content Percentage of Biomass Solid Fuels at different particle sizes and different mixing Ratios.

Higher Heating Values (HHV): The higher heating value or otherwise called calorific value is an integral aspect of any biomass solid fuel. It indicates the total energy dispensed of the samples. Figure 5 shows the HHV of the briquette fuel samples at different mixing ratios. Briquette(s) $350 \mu \mathrm{m}$ (70:30) have the highest 
calorific value, followed by $350 \mu \mathrm{m}$ (90:10) and 250 $\mu \mathrm{m}$ (80:20), respectively. The biomass solid fuels with least heating values are $150 \mu \mathrm{m}$ (90:10), followed by $250 \mu \mathrm{m}(90: 10)$ briquettes. It could be seen that grain particles of the palm kernel shell as well as higher amount of mesocarp fibre is probably responsible for the better HHV of series $350 \mu \mathrm{m}$. Figure 5 therefore shows that the bigger the grain particles, the higher the heating value of the solid fuels. All the solid fuels produced from the present study has a better HHV when compared with similar biomass solid fuels (agglomerates of PKS and PF) as reported by Chin Yee and Shiraz (2013) (Table 1). Moreover, one major parameter that could hinder the calorific value of any solid fuel is the choice of binder used. The slight difference in the heating value of this work and that of Chin Yee and Shiraz (2013) could be associated with the waste paper used as binder in their work. Furthermore, they reported that briquettes without binder display better heating value to those with binder. Perhaps, this could be the reason for the closeness in values obtained for this work. Apart from coal whose calorific value $(21.2563 \mathrm{~kJ} / \mathrm{g})$ has been proven to be high, values obtained for corn cob, groundnut shell (Onuegbu et al., 2010) and spear grass (Ilochi, 2010) are lesser when compared with the results obtained for the present work as shown in Table 1.

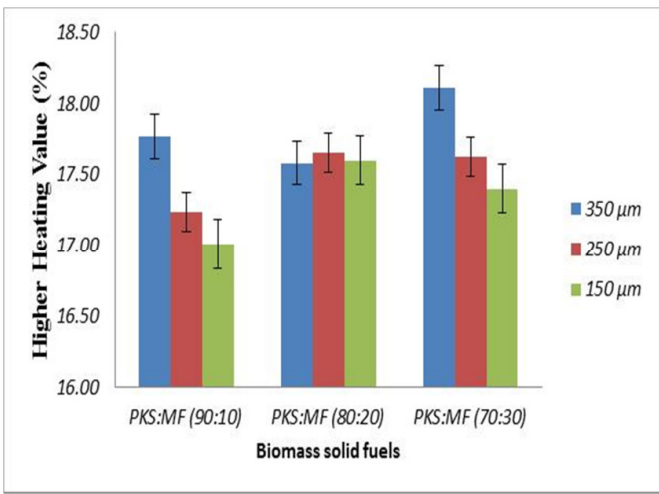

Fig. 5: Higher Heating Values of PKS: MF at different Mixing Ratios and Particle Sizes.

Conclusion: The results from this study revealed that oil palm wastes (varying mixture of PKS and MF) can be used to produce a supplementary energy source that can help to fix the energy mix challenges in the country and also reduce environmental pollution.

Acknowledgements: The authors will like to appreciate the immense efforts of Mr. O. O. Olawuyi and Tgst. Yusuf AbdulGaniyu of the Civil Engineering department and the entire staff of Mechanical and Materials and Metallurgical Engineering Departments, University of Ilorin, Nigeria.

\section{REFERENCES}

Akinbami, JFK (2001). Renewable energy resources and technologies in Nigeria: Present situation, future prospects and policy framework. Energy/Environment analysis group, centre for energy resource and devevelopment, Obafemi Awolowo Univ., Ile-Ife, Nigeria, Pp. 164.

Akowuah, JO; Kemausuor, F; Mitchual, SJ (2012). Physico-chemical characteristics and market potential of sawdust charcoal briquette. Int. J. of Energy and Environ. Eng. 3:20.

Chan-Mo, P (2010). Green technology:A basis for low carbon green growth paradigm for Korea, nat. res. foun., (jsp green innovation symposium, Tokyo).

Chin Yee, S; Shiraz, AM (2013). A study of biomass fuel briquettes from oil palm mill Residues. Asian Journal of Science Resource 6(3): 537545.

Eboatu, AN; Amanfor, I; Akpabio, IOJ (1992). Journal of Applied Polymer Sci. 44: 241.

Eboatu, AN; Garba, B; Akpabio, IOJ (1993). Fire and Materials. 17: 40.

Fujii, Y; Yamaji, K (1998). Assessment of technological options in the global energy system for limiting the atmospheric $\mathrm{CO}_{2}$ concentration. Environ. Econ. and Pol. Stu. 1: 113-139.

Ilochi, NO (2010). Comparative analysis of coal briquette blends with groundnut shell and maize cob. M.Eng. Thesis sub. to the dep. of P. and Ind. Chem., Fac. of Phy. Sci., Nnamdi Azikiwe University, Awka, Nigeria.

International Environmental Technology

Centre, (2009). Converting waste agricultural biomass into a resource. Report Number: DTI/1203/JP, Uni. Nat. Environ. Prog., Div. of Tech., Ind. and Econ., Osaka/Shiga, Japan.

Jean and Owsianowski, R (2009).Bio-Coal Out of Firebreak and Agricultural Residue: Between Forest Protection Management and Local Household Fuel Supply, Prog. for Rural Electrification And Sust. Mgmt. of Household Fuels (PERACOD) Dakar, Senegal (www.peracod.org).

Kaliyan, N; Morey, RV (2006). Factors Affecting Strength and Durability of Densified Biomass Products, Dep. of Bio-prod. and Bio-sys. Eng., Uni. of Minnesota, USA. 
Onuegbu, TU; Ogbu, IM; Ilochi, NO; Ekpunobi, UE; Ogbuagu, AS (2010). Enhancing the properties of coal briquette using spear grass (Imperata Cylindrica), Leo. J. of Sci. 17: 47-58.

Parikh, J; Channiwala, SA; Ghosal, GK (2005). A correlation for calculating HHV from proximate analysis of solid fuels. Fuel. 84: 18.

Piersol, RJ (1948). Briquetting Illinois; coals without binder. State Geological Survey. Bulletin, 72: 3435.

Plumer, B (2014). Why Oil Prices Keep

Falling - And Throwing the World into Turmoil. http://www.vox.com/ 2014/12/16/7401705/oilprices-falling (Accessed on January 19, 2015).
Shaha, AK (1974). Combustion; engineering and fuel technology. Oxford \& IBH Publishing Company. (Accessed August 31, 2014).

Ugwu, KE; Agbo, KE (2011).Briquetting of palm kernel shell. J. of Appl. Sci. Environ. Manage. 15(3): $447-450$.

United Nation Environmental Programme, (2006). Energy efficiency guide for industry in Asia. Stock Number: DTI/0752/PA. http://www.energyefficiencyasia.org. (Accessed August 31, 2014) 